\title{
An experimental study on the springback in bending of w-shaped micro sheet-metal parts
}

\author{
Wan-Adlan Wan-Nawang ${ }^{1, a}$, Yi Qin ${ }^{1}$, and Xiaoyu Liu $^{2}$ \\ ${ }^{1}$ Design Manufacture and Engineering Management Department, Univ. of Strathclyde, 75 Montrose \\ Street, Glasgow G1 1XJ, UK \\ ${ }^{2}$ School of Manufacturing Science and Engineering, Sichuan University, Chengdu 610065, China
}

\begin{abstract}
In sheet-metal bending, defects relating to the component-forms such as springback are common. This is due to the elastic deflection that occurs in the material after the bending process takes place. The objective of the research is to study on the springback behaviour in micro sheet-metal parts. This paper reports an investigation concerning the influence of the material rolling direction on springback in the case of w-shaped bending parts. Micro bending parts using $316 \mathrm{~L}$ annealed stainless steel strips having thickness of $50 \mu \mathrm{m}, 75 \mu \mathrm{m}$ and $100 \mu \mathrm{m}$ respectively were formed. The tensile and bending behaviours of the parts were observed through the experiment by considering the effect of rolling direction and size-effect related errors. The results revealed that various parameters influence the springback, such as thickness of the sheet, force applied, material rolling-direction and holding time during the sheet-deformation. The scale of the springback was also observed to be random among the parts made with a same sheet material.
\end{abstract}

\section{Introduction}

Regarding precision sheet-metal forming, products such as flat springs, spring clips, micro connectors, micro grippers, etc. have served many industries, from aerospace, medical to electronics industries; these products may be small, complicated and commonly consist of several challenging features to manufacture because of their sizes.

There are many important factors worthy being mentioned when describing a micro manufacturing process. While miniaturizing the product, one needs to consider size effect, force applied, lubrication condition, bending of micro part, tooling, material handling, etc. [1]. The size effect occurs when the part and the process parameter were scaled down, thus the design cannot follow the rules normally used for macro forming. It was also found that many other conditions would be affected when the part is scaled down, such as friction, loading and surface characteristics [2-4]. Size effect has been studied intensively, recently. However, few studies have been made to address springback in the microforming. A study used pure copper as the study material [5] the thicknesses of which ranges from $0.1 \mathrm{~mm}$ to $0.6 \mathrm{~mm}$. The study showed an effect of the grain size on springback.

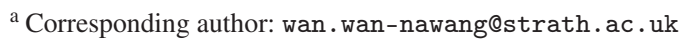

This is an Open Access article distributed under the terms of the Creative Commons Attribution License 4.0, which permits unrestricted use, distribution, and reproduction in any medium, provided the original work is properly cited. 


\section{MATEC Web of Conferences}

One of the common problems associated with sheet metal bending is springback. Springback is the geometric change made to a part at the end of the forming process when the part has been released from the forces applied through the forming tool. Upon completion of sheet metal forming springback affects the dimensional accuracy of a finished part. In conventional sheet metal forming, for example, many methods have been developed to control springback such as over-bending and corner-setting where the metal in the corner is made to flow plastically and set up compressive strains that overcome the strains contributing to the springback [5]. The springback depends significantly on the material behaviour and the ratio of bending radius to the sheet thickness. Variation in sheet thickness and material properties would lead to a variation in the bending angle after the load is removed [6]. Nevertheless, springback in micro-sheet-bending would involve more important factors to be taken into account.

\section{Experimental procedures}

To investigate springback in micro bending, a study was made on a complex form of bending which is commonly found in the type of product mentioned above using a very thin sheet metal. Thus, an intricate part which consists of bending with springback characteristics was chosen. The experimental design consisted of obtaining bend parts with $80^{\circ}$ bending angles. The experimental procedure had two stages. In the first one, the experimental study concerned material property characterisation by tensile test. Stainless steel sheets (SS 316L) with three different thicknesses of $100 \mu \mathrm{m}, 75 \mu \mathrm{m}$ and $50 \mu \mathrm{m}$ were tested. Tensile specimen were prepared from strips cut at $0^{\circ}, 45^{\circ}$ and $90^{\circ}$ to the rolling direction of the strips respectively. The experiments were carried out using a universal tensile machine. In the second stage, bending parts were formed on a micro forming machine. The bending specimen parts have identical thicknesses as that tested in the tensile tests. To produce the bending parts, a die with radii of $0.35 \mathrm{~mm}$ and $0.15 \mathrm{~mm}$ and "W" shape was inserted into a micro-stamping tool-set. The punch had $0.1 \mathrm{~mm}$ radius. The main parameters of the bending which were considered are the thickness of the sheets, material orientation and the force applied. The measurement and observation of the bent parts were carried out using a Mitutoyo optical measuring machine and Hitachi S-3700 Tungsten Filament Scanning Electron Microscope (W-SEM).

\section{Results and discussion}

\subsection{Yield strength of the material}

The results of the tensile test shown in Fig. 2 show that the yield strength of the $100 \mu$ m sheet metal has some variation with different rolling directions. The sample cut along the $0^{\circ}$ to the rolling direction has the highest yield strength. The material with the thickness of $75 \mu \mathrm{m}$, however, did not have any significant variation in yield strength for different rolling directions. It may suggest that in spite of that the material rolling direction normally plays a significant role in prescribing the material's yield strength, there are more factors that would contribute to it, such as the grain sizes and grain boundaries, especially at a lower length-scale.

\subsection{Observed deformations and defects}

Visual inspection was carried out on the samples using an SEM and an optical measuring machine.

The parts observed under the SEM and the optical measurement machine show clearly surface defects depending on the bending direction against the rolling direction of the material. It may be normal for large-sized parts made from bending. However, it is more severe for the thinner parts subjected to the bending. Larger springback occurs in thinner sheet-metals, as shown in the Fig. 4c). 


\section{ICNFT 2015}

a)

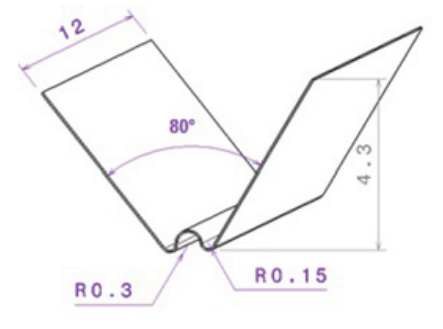

c)

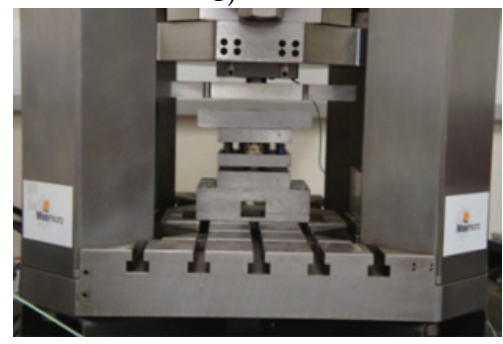

b)

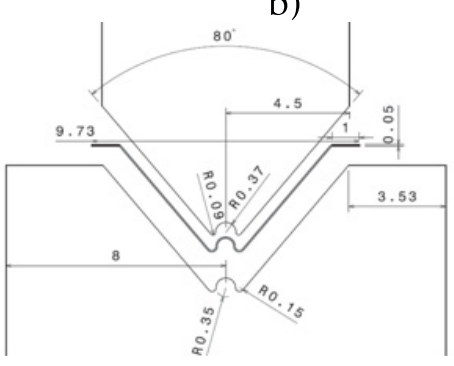

d)

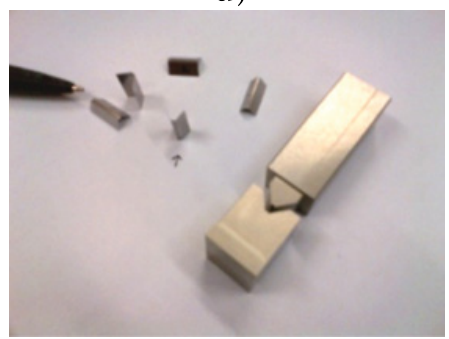

Figure 1. a) Dimensions of the part; b) Dimensions of the punch and die; c) the forming machine used; and d) the punch and die, and sample parts produced.

a)

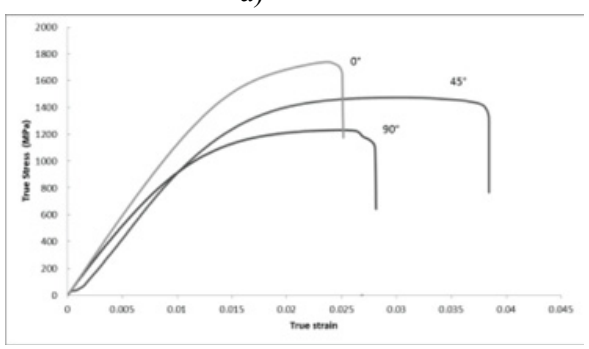

b)

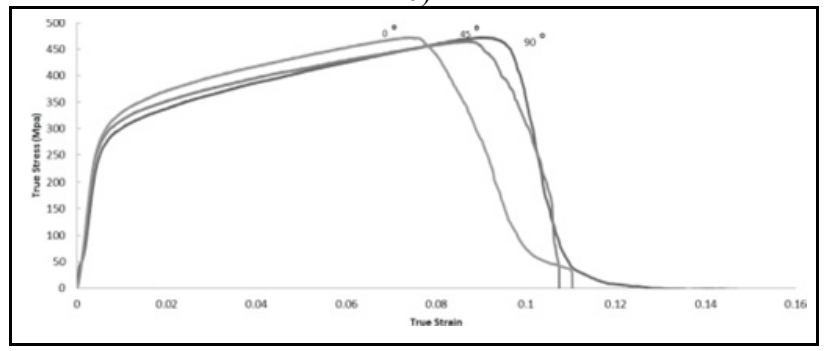

Figure 2. Yield strength of $316 \mathrm{~L}$ stainless steel with different material orientations and thicknesses: a) $100 \mu \mathrm{m}$; b) $75 \mu \mathrm{m}$.

a)

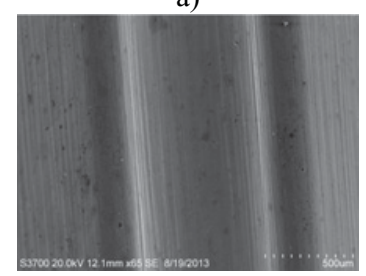

b)

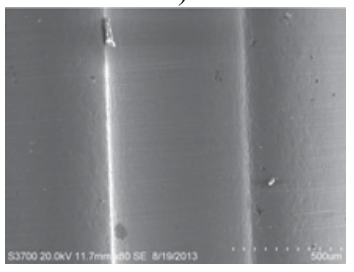

c)

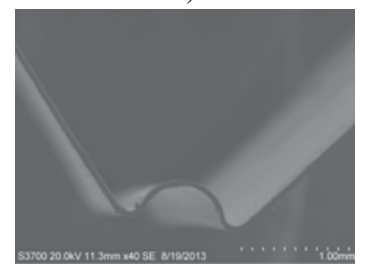

d)

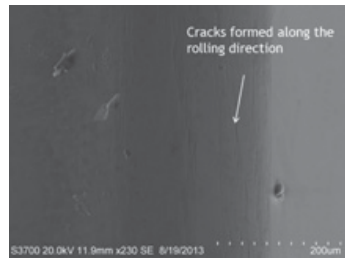

Figure 3. a) Bends made along the rolling direction $\left(0^{\circ}\right)$; b) bends made across the rolling direction $\left(90^{\circ}\right)$; c) a part observed under SEM; d) surface cracks formed along the bending and rolling direction. 
a)

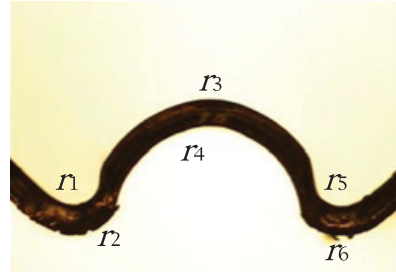

b)

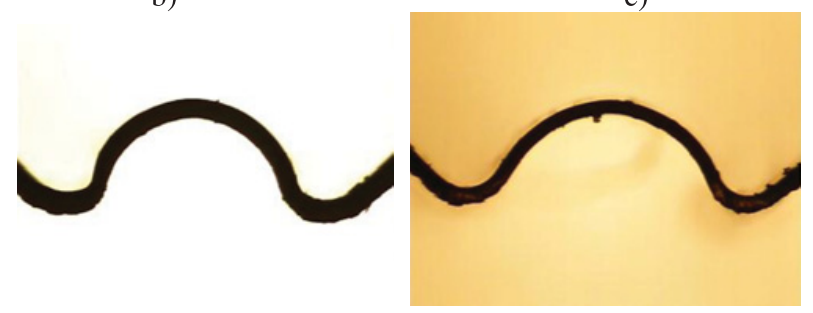

Figure 4. Material deformations observed (thinning and springback): a) $100 \mu \mathrm{m}$; b) $75 \mu \mathrm{m}$ and c) $50 \mu \mathrm{m}$.

a)

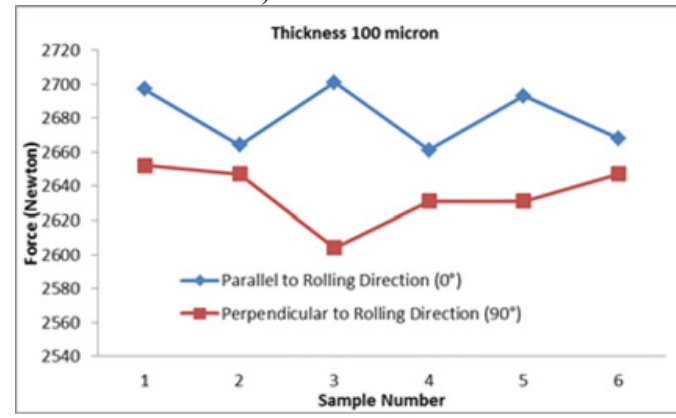

b)

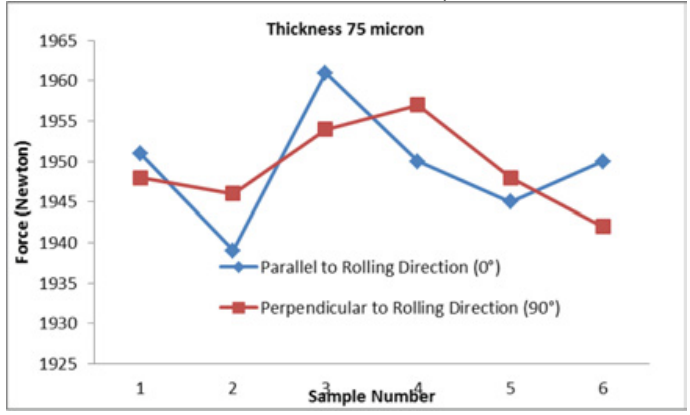

c)

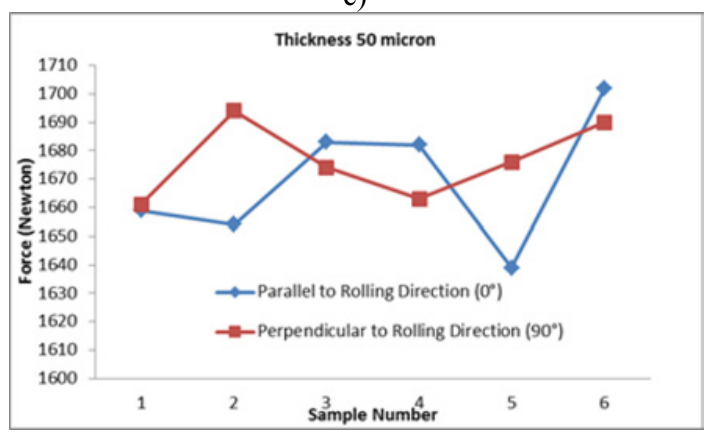

Figure 5. Relationship between the forming force and bending direction for: a) $100 \mu \mathrm{m}$, b) $75 \mu \mathrm{m}$ and c) $50 \mu \mathrm{m}$ in thickness.

\subsection{Effect of bending direction}

To study effect of the rolling direction on the forming force requirement, the samples were made with bending direction parallel $\left(0^{\circ}\right)$ and perpendicular $\left(90^{\circ}\right)$ to the material rolling direction respectively, while all other parameters remained constant. The result given in Fig. 5 showed that the force required for bending the material at $0^{\circ}$ is slightly higher, comparing to the bending made at $90^{\circ}$ to the material rolling direction for the sheet with a thickness of $100 \mu \mathrm{m}$. However, as the thickness of the samples decreased the forces measured had much similar values among the parts made with different bending directions. This result may suggest that when the sheet-thickness decreases to less than $100 \mu \mathrm{m}$, the bending direction has less effect on the forming force requirement. 
a)

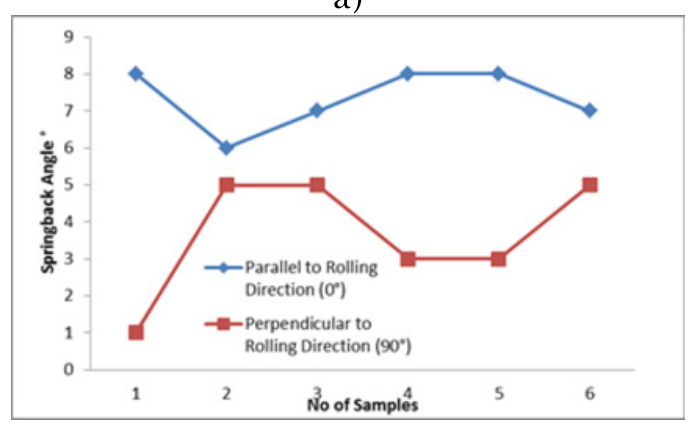

b)

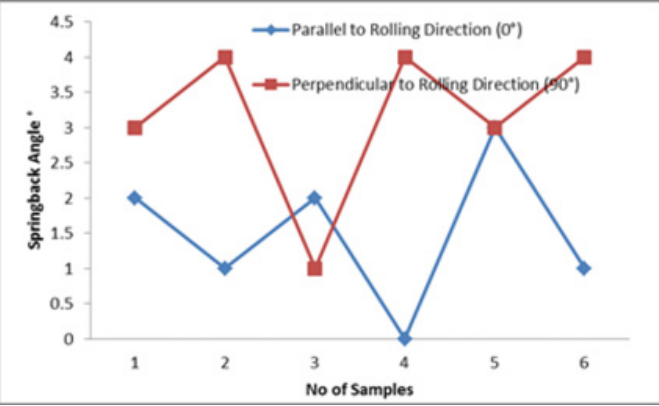

c)

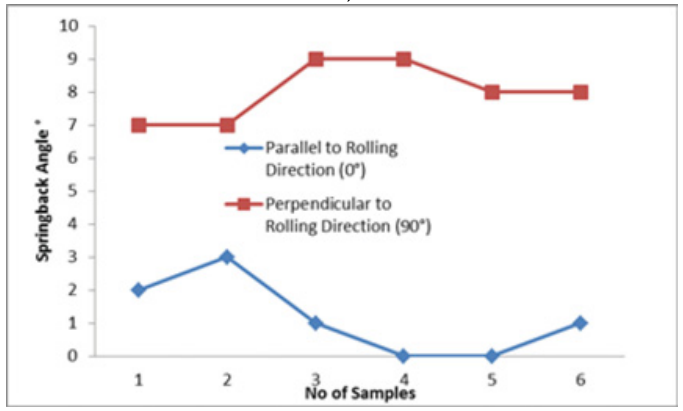

Figure 6. Springback angles produced with different bending directions for: a) $100 \mu \mathrm{m}$, b) $75 \mu \mathrm{m}$ and c) $50 \mu \mathrm{m}$ in thickness.

\subsection{Springback angle}

Springback angles of the parts formed were measured with the optical measuring machine. Figure 6 shows that springback of the specimens was seen to vary from $1 \%$ to $11 \%$ of the design angle, with a maximum springback angle of $9^{\circ}$. The result shows that, in general, as the sheet-thickness decreases the springback angle would increase. However, this does not always occur for the bending of thin sheet metals. As indicated in the Fig. 6, amounts of the sprinback along the different bending directions for different sheet-thicknesses have complex paterns. For example, the bend made at the $90^{\circ}$ showed a smaller springback for $50 \mu \mathrm{m}$ thick sheets while $100 \mu \mathrm{m}$ samples exhibit a dissimilar behaviour. This phenomenon further explains the size effect existing with forming of thin sheet-metals [7, 8]. Another fact which cannot be ignored at the micro-forming is that the springback observed among different samples obviously appear randomly distributed, and it is of a stochastic nature. Due to this, the method to be used for compensation for the springback to achieve higher precision of the formed part has to take this factor into account. A mechanical compensation method seems to be of a great challenge.

\subsection{Effect of holding time on springback}

Another experiment was made to examine the effect of bending holding time on the springback of the thin sheet metals. It shows that the springback angle varies significantly with different holding times for the $50 \mu \mathrm{m}$ thick stainless sheets (Fig. 7). Since those bendings were carried out at room temperature conditions, normal creep-deformation may not be a dominant factor in such a case. Interactions among grains and grain boundaries during the plastic flows to complete the geometric configuration of the part in such a mamner at the micro-scale need to be investigated in detail. 
a)

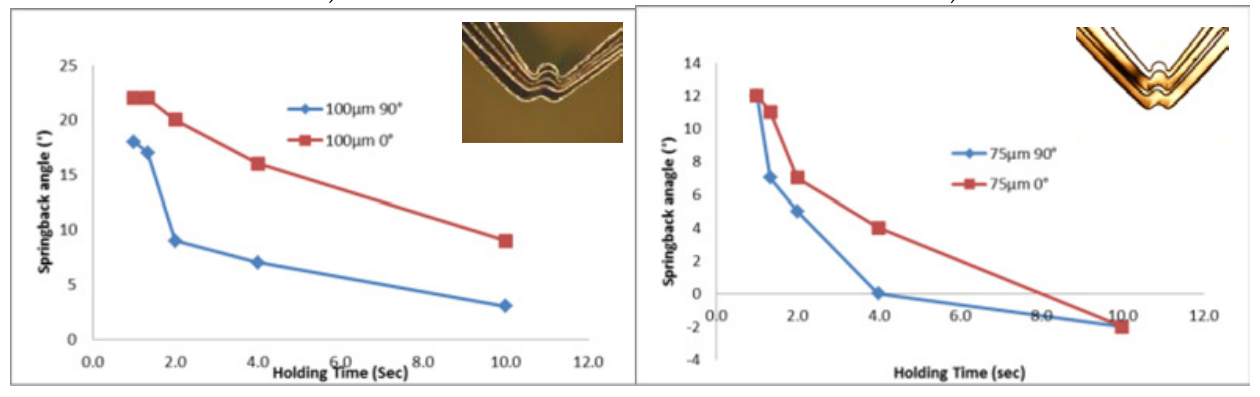

c)

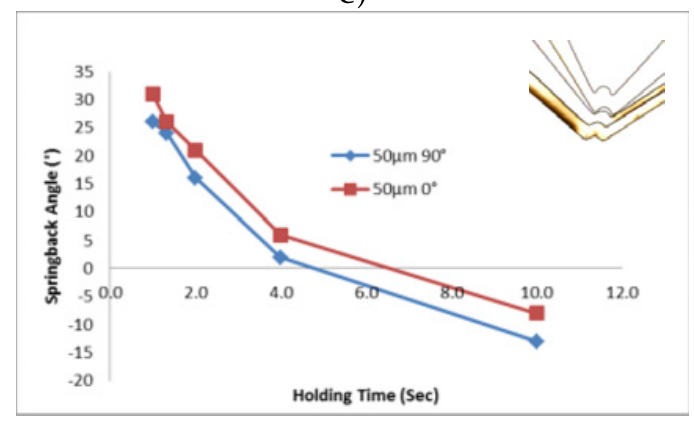

Figure 7. Effect of bending-holding time on the springback: a) $100 \mu \mathrm{m}$, b) $75 \mu \mathrm{m}$, and c) $50 \mu \mathrm{m}$, and the image on the right side of each graph shows the variation of springback angles produced with different holding times.

\section{Conclusions}

There are many parameters that determine springback during micro-sheet-forming involving bending, which makes it more difficult to control geometric accuracy of the part formed. A significant amount of the springback is observed in the thinner sheet metals. But this is not always the case. The trend of the influence clearly depends on the thickness of the sheet and orientation of the bending against the material rolling direction. Grain size, orientation and grain boundary condition certainly play significant roles on it. The holding time has also been identified to be a factor contributing to the extent of the springback and hence, influencing the accuracy of the final part formed. While considering effects of some key factors, one cannot be ignored is that the springback in micro-scale forming is of stochastic nature, which is largely due to that grain-size and orientation distribution are of such a nature. As a consequence, compensation for the springback related forming-errors in micro forming is of certain challenges.

\section{References}

[1] Qin, Y., Chapter 1 - Overview of Micro-Manufacturing, in Micro-Manufacturing Engineering and Technology, Y. Qin, Editor 2010, William Andrew Publishing: Boston

[2] Deng, J.H., M.W. Fu, and W.L. Chan, Size effect on material surface deformation behavior in micro-forming process. Materials Science and Engineering: A, 2011

[3] Gau, J.-T., C. Principe, and J. Wang, An experimental study on size effects on flow stress and formability of aluminm and brass for microforming. Journal of Materials Processing Technology, 2007 


\section{ICNFT 2015}

[4] Li, H., et al., Size effect on springback behavior due to plastic strain gradient hardening in microbending process of pure aluminum foils. Materials Science and Engineering: A, 2010

[5] Cyril Donaldson, G.H.L., V C Goold, Tool Design, ed. T. Edition2001, New Delhi: Tata Mc GrawHill

[6] Garcia-Romeu, M.L., J. Ciurana, and I. Ferrer, Springback determination of sheet metals in an air bending process based on an experimental work. Journal of Materials Processing Technology, 2007

[7] Albut, A. and G. Brabie, The influence of the rolling direction of the joined steel sheets on the springback intensity in the case of $O$-shape parts made from tailor welded strips. Archives of Civil and Mechanical Engineering, 2006

[8] Nakano, M., et al., Relationship between rolling direction and texture in thin grain-oriented 3\% silicon sheets. Journal of Magnetism and Magnetic Materials, 1999 